\title{
The Business Canvas*
}

\section{An Emerging Visual Genre of Professional Communication}

\author{
Mason T. Pellegrini ${ }^{\dagger}$ \\ English Department, Purdue University, West Lafayette, Indiana, USA \\ pellegrm@purdue.edu
}

\begin{abstract}
Many entrepreneurs are moving away from creating traditional written business plans as they are too expensive and timeconsuming to create, and they are instead using the streamlined visual invention tool known as the business canvas to articulate the details of their business. This article describes what business canvases are, covering the two main types of canvases and their characteristics. Then, the article provides a case study which illustrates how canvases can be used. I argue that this important visual genre is under researched and could have important pedagogical uses in professional and technical writing.
\end{abstract}

\section{CCS CONCEPTS}

- General and reference $\rightarrow$ Document types; General conference proceedings; • Human-centered computing $\rightarrow$ Visualization; Visualization systems and tools; • Social and professional topics $\rightarrow$ Professional topics.

\section{KEYWORDS}

Entrepreneurship, business canvas, business model canvas, lean canvas, innovation, visual communication, workplace writing

\section{ACM Reference Format:}

Mason T. Pellegrini ${ }^{\dagger}$. 2021. The Business Canvas ${ }^{\star}:$ An Emerging Visual Genre of Professional Communication. In The 39th ACM International Conference on Design of Communication (SIGDOC '21), October 12-14, 2021, Virtual Event, USA. ACM, New York, NY, USA, 7 pages. https://doi.org/10. $1145 / 3472714.3473645$

\section{INTRODUCTION}

In the increasingly competitive world of business, new companies need to leverage resources more effectively than ever and must often dramatically reimagine their business (i.e., pivot) several times before achieving steady revenue. Therefore, many entrepreneurs are moving away from creating traditional written business plans as they are too expensive and difficult to revise, and they are instead using the streamlined visual invention tool known as the business canvas to articulate the details of their business. There are many types of business canvases, but the business model canvas (BMC) and the BMC's variant, the Lean Canvas (LC), are the most popular. Despite the wide use of business canvases and the important role

Permission to make digital or hard copies of part or all of this work for personal or classroom use is granted without fee provided that copies are not made or distributed for profit or commercial advantage and that copies bear this notice and the full citation on the first page. Copyrights for third-party components of this work must be honored.

For all other uses, contact the owner/author(s).

SIGDOC '21, October 12-14, 2021, Virtual Event, USA

(c) 2021 Copyright held by the owner/author(s).

ACM ISBN 978-1-4503-8628-9/21/10.

https://doi.org/10.1145/3472714.3473645 they play in business and entrepreneurship, no professional and technical communication (PTC) scholarship investigates this visual genre and its uses in generating, iterating, and communicating business models to varied stakeholders.

That is the purpose of this research paper. The first section of this paper will cover what the BMC and the LC are, how business canvases are used, and will summarize business canvas research in disciplines outside PTC. The second section of this paper offers a case study that illustrates how entrepreneurs can use business canvases. This case study narrates my experience working with a startup called FlykeART as the company navigated the process of acquiring funding for a university-based startup in the US. I detail how these student entrepreneurs won $\$ 5000$ in equity free funding by competing in a business canvas-based pitch competition and also how they used the LC to effectuate a major pivot in their business. I argue that this case study illustrates the two main ways in which business canvases are used to communicate: internally and externally. I conclude by pointing to possible pedagogical uses of business canvases in PTC courses.

This paper is connected to the conference theme by investigating an emerging industry tool used across global contexts by entrepreneurs to form coalitions. A strong business model as articulated by a BMC can be a rallying point for an emerging business, and resource conscious methods of entrepreneurship like the BMC and LC are particularly necessary for entrepreneurs with less access to funding and intellectual property such as social entrepreneurs and those from marginalized groups. Use of the FlykeART case study was approved by Purdue University's institutional review board and also by FlykeART managing director Juan Pablo Mascaretti.

\section{BUSINESS CANVASES}

\subsection{What is the Business Model Canvas?}

The Business Model Canvas was popularized by Swiss business theorist Alexander Osterwalder and Belgian computer scientist Yves Pigneur. While the initial idea for the BMC came from a blog post that Osterwalder posted on his personal website in November 2005 [1], Osterwalder and Pigneur's 2010 book Business Model Generation: A Handbook for Visionaries, Game Changers, and Challengers is the most well-known place that the BMC is described. Since that book was published, the BMC has become a very popular concept globally in both entrepreneurship and business and has been written about in innumerable websites and books.

The BMC is simply nine boxes all of which appear situated together in one large rectangle. Osterwalder and Pigneur refer to the boxes as "building blocks," and each represents an important dimension of the business model [2]. The BMC, like all business canvases, is simply a heuristic tool to help someone think about a business 


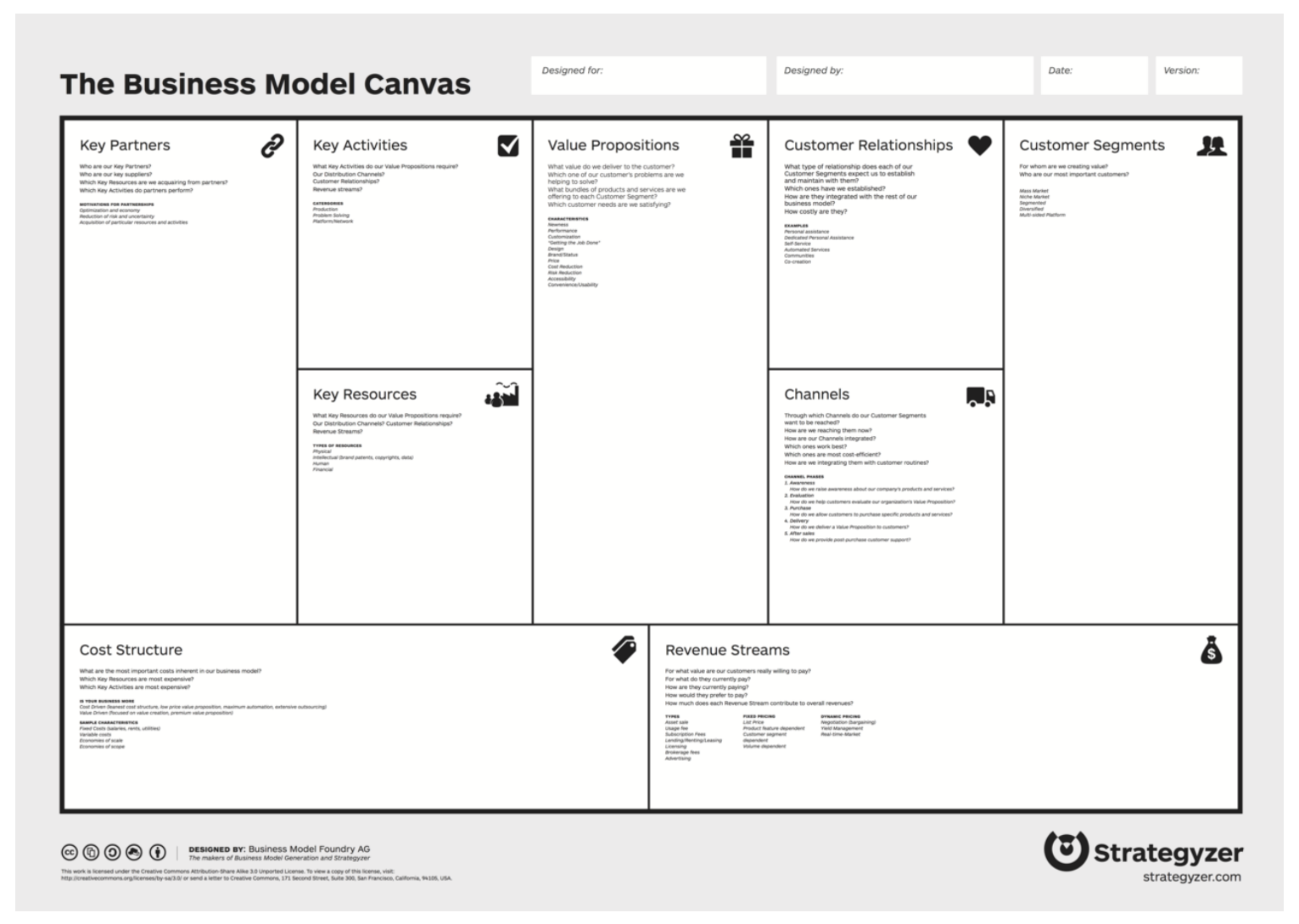

Figure 1: A blank business model canvas with boxes labelled taken from strategyzer.com

more effectively and comprehensively. The BMC is freely available for entrepreneurs to use under a Creative Commons license. Figure 1 is a blank BMC from strategyzer.com, which is Osterwalder's website.

Though the BMC in Figure 1 is not filled in with the details of a company's business model, it has each of the building blocks labelled to indicate which part of the business model should be written about there. Also, this particular BMC has questions to help an entrepreneur generate the content for each box. Not every BMC is like this - sometimes, an entrepreneur may use a blank BMC that has no text on it at all, or a BMC that only has the name of each of the building blocks. Now, as outlined by Osterwalder and Pigneur, I will describe what an entrepreneur writes in each of the BMC's empty boxes (i.e., in each of the building blocks) [2]:

- Customer segments: The different groups of customers that the business is targeting, the characteristics of these segments, and their needs that the business is fulfilling.

- Value propositions: The services and/or products that encourage a customer to choose one company over another, the way customer needs are fulfilled. Often, value is created through improving previous offerings in an industry or even finding a new way to offer value.

- Channels: How a company interacts with and delivers its value propositions to its customers.
- Customer relationships: The type of relationship the company has with its customers, the level or form of human or automated interaction that customers receive when interacting with the company.

- Revenue streams: The money that is generated by the customers. This is usually broken into recurring and one-time transactions.

- Key resources: The most important resources required for a company to operate. These do not necessarily need to be physical assets, but can also be "financial, intellectual, or human" [2].

- Key activities: The most important activities that keep a company operating. Activities vary widely depending on the company's business model and can be creating physical products, solving customer problems, or networking customers and maintaining a platform.

- Key partnerships: Relationships with different companies that allow the company to function. Generally, these other companies are grouped as either resource suppliers or strategic partners.

- Cost structure: The costs that a business incurs while operating. This can be in purchasing resources or in maintaining key activities. 


\subsection{What is the Lean Canvas?}

Though the BMC is the most widely used business canvas, it is far from the only business canvas. There are many variations of the BMC optimized for specific types of businesses like the Social Enterprise Model Canvas for social entrepreneurial ventures [3] or the Ecocanvas for environmentally focused ventures [4]. There are even variations of the BMC for non-business uses such as the Personal Growth Canvas for self-improvement [5]. The most popular variation of the BMC, however, is the Lean Canvas, which was popularized by entrepreneurial author Ash Maurya in his 2010 book Running Lean: Iterate from Plan A to a Plan that Works. Maurya is an influential figure in the lean startup movement, which is focused on minimizing waste in the creation of businesses, products, and services. Maurya's purpose for creating the LC was to adapt the $\mathrm{BMC}$ for startups that use lean startup methodology.

There are many similarities between the BMC and the LC. To start, when the boxes or "building blocks" are not labelled, the two canvases are visually identical. They have the same number of boxes, and the boxes are the same shape as one another. In addition to the visual similarities, six of the nine boxes of the LC have the same or very similar content when compared to the BMC. Below, I list the boxes of the LC that are similar to the BMC, and I also note when there are differences between the two. This content comes from chapter three of the second edition of Running Lean by Ash Maurya.

- Customer segments: Mostly the same as "customer segments" on the BMC, but the LC specifically asks the entrepreneur to also identify the characteristics of potential early adopters as a subset of the customer segments.

- Channels: The same as "channels" on the BMC.

- Revenue streams: The same as "revenue streams" on the BMC.

- Cost structure: The same as "cost structure" on the BMC.

- Unique value proposition: Mostly the same as "value proposition" on the BMC, but with more of a focus on differentiating from other companies. As a subset of this box, Maurya also asks entrepreneurs to define a "high-level concept," which is a combination of ideas that makes it easier for people to understand what the company does. Some examples that Maurya provides are "YouTube: 'Flickr for video"' or "Aliens (movie): 'Jaws in space"' [6].

- Key metrics: Similar to "key activities" on the BMC, but "key metrics" is oriented towards using data to track progress, which is an important feature of lean methodology.

Despite these important similarities between the BMC and the $\mathrm{LC}$, these canvases are far from identical. The remaining three boxes of the LC differentiate the BMC from the LC to a larger degree, and they replace the "key partners," "key resources," and "customer relationships" building blocks on the BMC.

- Problem: The top problems that the targeted customer segment needs solved. As a subset of this box, Maurya also asks entrepreneurs to identify "existing alternatives" which is the products or services customers are currently using to solve their problem [6].
- Solution: The solution is how the entrepreneur's product or service solves the problem. Usually, this is articulated as specific features of the product or service.

- Unfair Advantage: A business advantage "that cannot be easily copied or bought" by a rival company [6].

Proponents of the LC claim that it is more customer and problem solving focused than the $\mathrm{BMC}$, and that it is more appropriate for early-stage ventures whereas the BMC is more fitting for established businesses. Additionally, they claim that the LC requires less expertise to use whereas the BMC requires a background in business [7]. A further note is that the LC is more aligned with the pitch structure entrepreneurs use while seeking investment, which also centers on solving problems for customers.

\subsection{How and Why are Business Canvases Used?}

Generally, business canvases are used the same way a written business plan is: their main use is as a reflective tool for entrepreneurs to clarify and record their ideas for starting a business. But a business canvas (or business plan) may accomplish more than this. After the canvas is created, it can serve as the heart of an emerging business around which a group of entrepreneurs focus their efforts and form a coalition. In essence, the business canvas is what the organization agrees upon and believes in - it is why the group of entrepreneurs has banded together. Therefore, upon becoming a part of a startup, individuals may refer to and attempt to internalize the business canvas to be onboarded into the organization more effectively. In fact, a well-made business model, as articulated by a canvas or plan, may serve as a lightning rod to attract people or funding into an organization without much effort on the part of an entrepreneur. Conversely, if a disagreement arises in the business, the change needs to be reflected in the canvas or the coalition will risk disintegrating.

While business canvases and business plans are similar in their role in building coalitions, there are important differences between the two genres. Many of these differences have contributed to the rising popularity of the business canvas. For example, canvases are much faster and easier to create than traditional written business plans, which can be as long as 100 pages. In contrast, Maurya wrote that a LC should be filled out in less than 15 minutes [6]. In my experience, filling out a canvas will often take longer than that, but they are still much easier to create than even a short business plan. Another advantage of canvases is that, unlike business plans, canvases force an entrepreneur to be concise when writing about their business: there is only so much one can write on a large sheet of paper. Conversely, business plans are notoriously long-winded. Since canvases are so easy to fill out, another key facet of canvases is that they are meant to be rapidly updated, which is an important in today's lean-oriented world of entrepreneurship with its focus on pivots. Another important difference between how business plans and business canvases are used is that business canvases are composed or discussed collaboratively more often than written business plans are. A business canvas can be printed on a large or small piece of paper for entrepreneurs to write or place sticky notes on, and entrepreneurs will often display business canvases on a whiteboard or projector, so they can more easily collaborate on a 


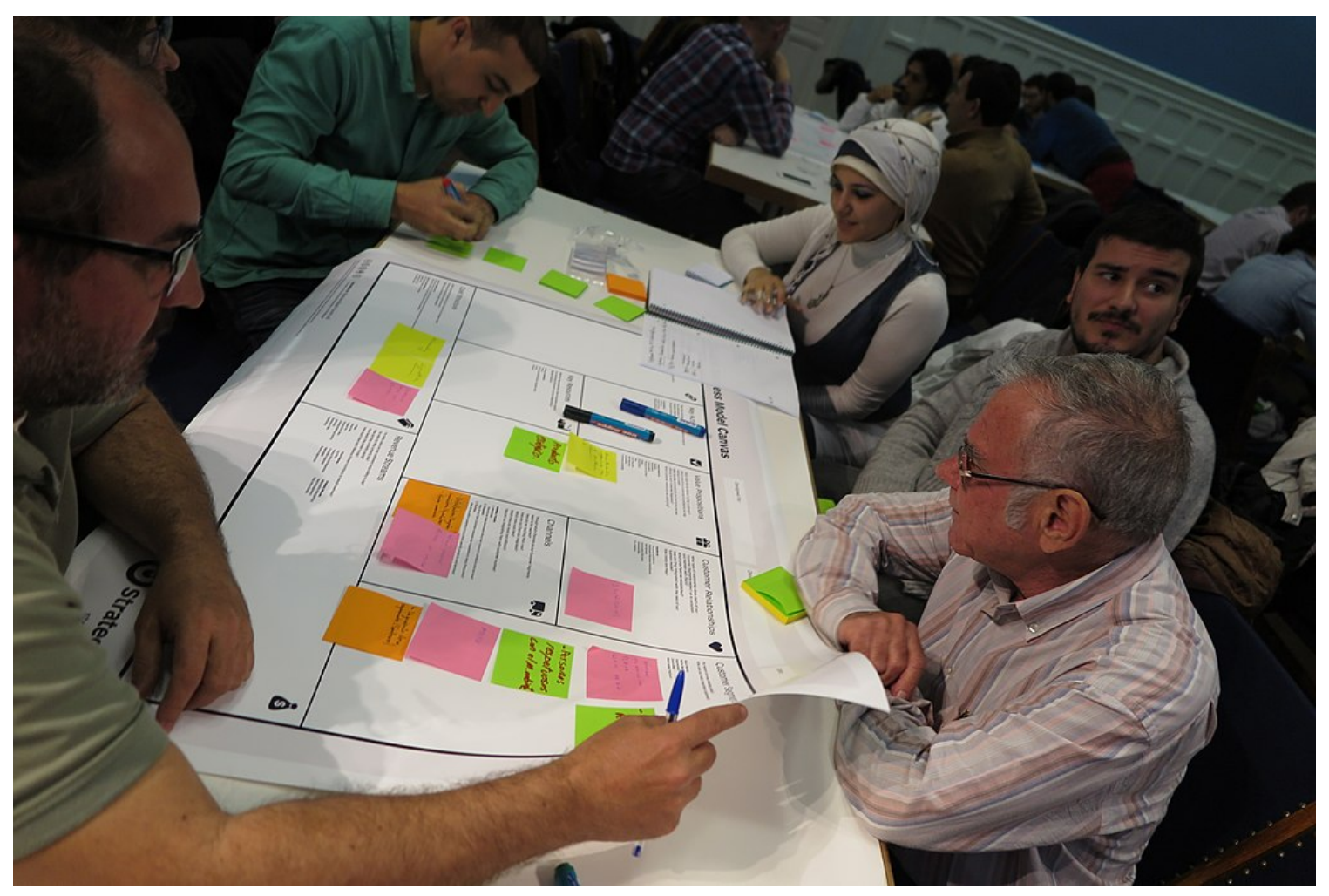

Figure 2: A BMC being used with sticky notes taken from commons.wikimedia.org

business idea together. Figure 2 is an image of a common way in which several entrepreneurs might work on a business canvas.

Some common spaces for canvases to be used in this manner include business schools, business incubators, and business accelerators to help entrepreneurs generate ideas for forming a business. Canvases can also be used within existing companies to try to create a new, innovative product or division of their company. Today, the use of business canvases is just as global and widespread as the written business plan $[2,7]$

\subsection{Scholarship on Business Canvases}

A lot of research has been published on business canvases, mostly focusing on the BMC. Much of this research on BMCs has come from the management discipline, and the most common topic in this area is the strengths and weaknesses of the using BMC as a method for starting businesses. For example, Coes studied entrepreneurs who used the BMC to develop their business models and found that the $\mathrm{BMC}$ worked well because it centralizes value creation in making a business, but that the BMC was limited in that it does not consider competition and only works for profit generating organizations [8]. Similarly, Ching and Fauvel argued that, while the BMC does help undergraduates create business models, a major shortcoming of the BMC is that it does not take competition into account [9]. Connected to these pedagogical uses of the BMC, another topic in business canvas scholarship is how the BMC can be used to teach entrepreneurship. To illustrate, Jackson et al. argued that the BMC works as a pedagogical tool to teach entrepreneurship students how to create business models as well as learn the financial aspects of a business [10]. Similarly, Türko analyzed the differences in student perceptions of the BMC as compared to a written business plan. She found that students thought that the BMCs were easier to make overall, but that written business plans provide better and more detailed information [11].

There has been some research on the business canvas as a form of communication, but none of this research is within PTC. For example, Fritscher and Pigneur, explored the BMC as a tool to visualize changes in a business model over time [12], and Sort and Nielsen investigated how entrepreneurs use the BMC to communicate the details of their business more easily to angel investors [13]. The aim of this article is to fill in this gap of how business canvases are used as a form of communication by providing general information for a PTC audience on what business canvases are and how they are used. Next, I approach that task by using a case study to illustrate different situations in which canvases are used by entrepreneurs to communicate.

\section{CASE STUDY: FLYKEART AND THE LEAN CANVAS}

\subsection{Introduction}

In early spring 2019, I attended an entrepreneurial networking meeting on Purdue University campus. There, I saw two entrepreneurs, one graduate student and one undergraduate student, deliver a pitch 
for their company FlykeART. The purpose of the company was disrupting the airline food cart industry by creating a lightweight airline food cart that was digitally integrated with the plane's cabin through Wi-Fi. I approached the FlykeART team after the pitches had ended and offered them feedback on their pitch. The managing partner of FlykeART, Juan Pablo Mascaretti, was very receptive to the feedback and invited me to attend their weekly meetings. This was the start of my relationship with FlykeART, which would result in me learning about business canvases and also helping FlykeART to create pitches for several high-profile pitching competitions for university students.

\subsection{FlykeART at the International Business Model Competition}

When I first became affiliated with FlykeART, the startup had been preparing for a pitching competition called the International Business Model Competition (IBMC). In several respects, the IBMC was unusual when compared to other student pitching competitions I had been exposed to at that point. First, it was much bigger and more prestigious. In fact, promotional material for the event claimed that the IBMC was the "first \& largest lean startup competition in the world" [14]. That year, over 8000 teams had competed for the 40 finalist slots, each of which awarded the team an invite to Brigham Young University to compete for the top prizes. Every finalist team was awarded $\$ 2500$ for coming to the competition. The top prize was $\$ 40,000,2^{\text {nd }}$ prize was $\$ 25,000$, and $3^{\text {rd }}$ prize was $\$ 15,000$. All the winnings were equity free, which means that the IBMC was not getting anything in return for the money.

While the scope of the IBMC was different than what I was used to, the biggest difference, however, was the business philosophy behind the competition. As mentioned earlier, the IBMC was solely focused on lean methodology. As taken from their 2019 website on the internet archive:

"The IBMC is a unique student startup competition focused on the inputs, not the outputs, of the entrepreneurial process. The competition requires active identification and validation of crucial business model hypotheses rather than the writing of a static business plan, talking to customers outside the building rather than gathering secondary data inside the building, applying customer development rather than relying on product development, and 'pivoting' or changing course rather than executing on the plan" [14]

This focus had important consequences for how teams would pitch during the competition: the normal problem/solution structure of pitches would not succeed there. The website continues: "Submissions for the competition focus on the process entrepreneurs undertake as they test their most crucial hypotheses with customers and develop validated business models" [14]. In other words, each team's presentation would use a business canvas and other visual tools to tell the story of how they developed their business model through trial and error.

The week we prepared for the event was a whirlwind of activity. As the startup's entrepreneurial communication specialist, I analyzed the winning presentations from previous years to understand their structure and content. I learned that every pitch in that placed in the top three positions over the three previous years had used either a BMC or an LC as the focus of their presentation, and each pitch was formed as a series of changes to the business model (i.e., pivots) which resulted from gathering data from customers. All the while, presenters would tell the judges how they kept costs low in time and money. Most teams historically had used the BMC to tell the story of their business model, but we decided to use an LC since Ash Maurya created the LC and would be one of the competition's judges. Figure 3 is a modified version of the slide at the end of FlykeART's presentation which showed our final LC after all the pivots and validation.

The final version of the slide in Figure 3 had company logos, images, and icons to represent the different parts of the business model, which I removed to avoid copyright infringement, but the content is otherwise identical. The green boxes of the LC are parts that had been validated through customer discovery whereas the yellow boxes had not yet been validated. At the start of the pitch, none of the business model's assumptions were validated, and at the end, we showed that there were still some aspects of the business that we needed to gather data on despite the progress we had made. Throughout the pitch, the icons on the canvas changed to visually indicate how the business model had iterated. To showcase how much the company had pivoted, the presentation began with the earliest iterations of the product which was an autonomous airline serving robot. After each FlykeART pitch, judges asked questions about FlykeART's canvas, both to understand the business better and to check FlykeART's knowledge of lean entrepreneurship. Most companies used very similar strategies to FlykeART and had clearly studied the previous years' winning pitches as we had. FlykeART made it past the first bracket of pitches, placed in the top 10, and was awarded a $\$ 5000$ prize.

\subsection{FlykeART's Major Pivot}

Next, I will describe a more organic use of a business canvas. About six weeks after the IBMC, I arrived at one of FlykeART's weekly meetings where I saw the team engaged in animated discussion about an LC which was drawn on the meeting room's whiteboard. Figure 4 is an image of that LC.

FlykeART had decided to make a major change in its business strategy and was using the LC as a tool to articulate and discuss those changes. Since nearly the beginning, the company had worked to create a smart, lightweight airline food cart which connected to $\mathrm{Wi}$-Fi. Its value propositions were improving customer experience through algorithmically optimized catering and reducing operating costs through weight reduction, but upon gathering data from customers and working on their minimum viable product, the team had learned important lessons which made them think a different strategy would be more effective. First, the team had learned the difficulty of technologically accomplishing what they set out to do. Just engineering an airline cart that dramatically reduced weight but maintained durability and function was a very difficult task without also creating software that both customers and flight attendants would interact with. Therefore, FlykeART decided to drop the value proposition of optimizing catering to focus solely on reducing operating costs with a lightweight cart. Additionally, FlykeART had learned important information about the airline food cart industry. The world's major supplier of airline food carts 


\begin{tabular}{|c|c|c|c|c|c|}
\hline $\begin{array}{c}\text { Final } \\
\text { Canvas }\end{array}$ & \multirow{2}{*}{$\begin{array}{l}\text { Solution } \\
\text { FlykeART is a } \\
\text { lightweight and } \\
\text { digitally integrated } \\
\text { food cart. }\end{array}$} & \multirow{3}{*}{\multicolumn{2}{|c|}{$\begin{array}{l}\text { Unique Value } \\
\text { Proposition } \\
\text { FlykeART is a } \\
\text { smart airplane } \\
\text { food cart that } \\
\text { reduces operating } \\
\text { costs and } \\
\text { improves the } \\
\text { in-flight } \\
\text { experience. }\end{array}$}} & $\begin{array}{c}\text { Unfair } \\
\text { Advantage }\end{array}$ & \multirow{3}{*}{$\begin{array}{l}\text { Customer } \\
\text { Segments } \\
\text { The director of } \\
\text { operations in the } \\
\text { airline is our customer. } \\
\text { - Low Cost, short- } \\
\text { haul } \\
\text { International, long- } \\
\text { haul } \\
\text { Early Adopters: } \\
\begin{array}{l}\text { Southwest } \\
\text { United } \\
\text { AeroMexico }\end{array}\end{array}$} \\
\hline $\begin{array}{l}\text { Problem } \\
\text { The conventional food } \\
\text { carts are: } \\
\text { 1. Too heavy } \\
\text { 2. Inefficient } \\
\text { 3. Not integrated } \\
\quad \text { with the cabin } \\
\text { Existing Alternatives: }\end{array}$ & & & & Connects via Wi-Fi & \\
\hline $\begin{array}{l}\text { 2. Inefficient } \\
\text { 3. Not integrated } \\
\text { with the cabin } \\
\text { Existing Alternatives: }\end{array}$ & \begin{tabular}{l}
\multicolumn{1}{c|}{ Key Metrics } \\
Create lean canvas \\
\# Food carts supplied \\
\# FlykeAPP downloads \\
\# Meals ordered
\end{tabular} & & & $\begin{array}{l}\text { Channels } \\
\text { Direct and } \\
\text { Outbound }\end{array}$ & \\
\hline \multicolumn{3}{|c|}{$\begin{array}{l}\text { Cost Structure } \\
15000 \text { lines of code } * \$ 10 / \text { line }=\$ 150000 \\
\text { Lightweight aluminum body }=\sim \$ 650 / \text { cart } \\
\text { FAA certification }=\$ 15000 \\
\text { Design, utility and trademark patents }=\$ 35000 \\
\text { Break-even: } \sim 140 \text { carts sold }\end{array}$} & \multicolumn{3}{|c|}{$\begin{array}{l}\text { Revenue Streams } \\
\text { Lease carts for } \$ 2000 \text { down payment + } \\
\$ 710 / \text { mo. for } 24 \text { months } \\
\text { Software license/purchase transactions? } \\
\text { Ads? }\end{array}$} \\
\hline
\end{tabular}

Figure 3: Modified version of FlykeART's completed Lean Model Canvas slide as used at the IBMC

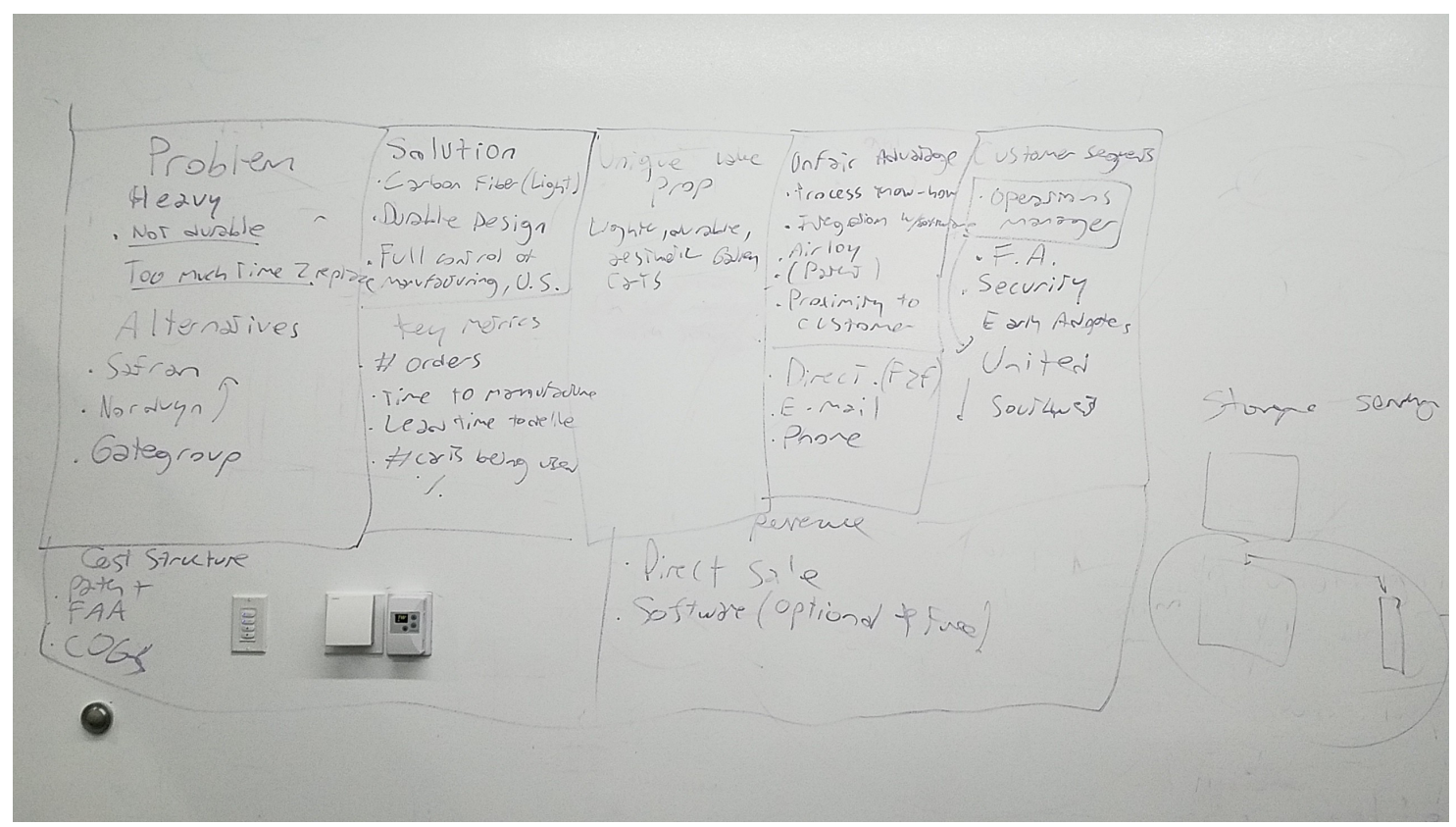

Figure 4: FlykeART's major pivot with the Lean Model Canvas

manufactured their carts outside the US, and sometimes American airlines would have to wait weeks to get shipments. As a result, a new part of their business model would be to take advantage of their proximity to American airlines to more quickly provide orders when airlines needed them. As FlykeART made these changes to their business, they wrote out the new aspects of the business 
model on the white board, using the language and concepts of the LC as the lens through which to think about their business.

\section{DISCUSSION AND CONCLUSION}

\subsection{The Main Categories of Canvas Use}

There are many more specific scenarios in which a business canvas might be used by a company, but I believe that these two examples represent the two main categories of use. The first is using a canvas as a tool to communicate with people external to a company. Businesses are complicated entities, and investors or mentors who want to learn about a startup often have the difficulty of being given too much information, being given the wrong information, and sometimes not being able to understand the basics of a startup, even after they listen to a pitch or read a business plan. The building blocks of a business canvas are widely understood by people in the business community, and they provide focus points around which an entrepreneur can provide details on what they want their company to accomplish to someone who may be interested in providing them funding or giving them feedback on their business model. This was the situation FlykeART found itself in during the IBMC.

The second use is employing a business canvas to communicate internally. This is when an entrepreneur or group of entrepreneurs is trying to generate a business plan for an entity that they want to form, or like FlykeART, they may be talking through changes that they might make to an existing business. Here, the boxes of a business canvas can ensure that an entrepreneur does not leave out any important aspects of a business while they are creating it. Additionally, when there is a group of entrepreneurs working together on a business, this use of a canvas can have the added benefit of keeping everyone on the same page. This is the previously mentioned function of canvases in building and maintaining coalitions. In both situations, a business canvas accomplishes what a written business plan cannot easily accomplish: it is much harder for an investor to quickly read a written business plan to decide whether they want to invest, and it is much harder for a group of entrepreneurs to collectively edit a lengthy written document while they are trying to envision or alter a new company.

\subsection{Business Canvases in PTC Classes}

Clearly, management or entrepreneurship-oriented PTC courses have more potential applications for business canvases. For example, a common assignment in entrepreneurial business writing is to have students collaboratively compose a written business plan for a hypothetical company, sometimes a business plan based on university intellectual property. A business canvas could be used as a prewriting activity for the larger written business plan, or even in place of the written business plan. Using a canvas might be particularly useful as a prewriting activity if the end goal was only to have students to deliver an oral business pitch rather than a written business plan. Multimodal elements can be integrated into the use of a business canvas as well. Frequently when entrepreneurs use canvases externally, images are placed on a business canvas to visualize the different elements of a business model. Lastly, similar to the IBMC, a business canvas could also be used by students during a customer validation project to visually illustrate how they have used customer discovery to collect data on different parts of their business model. A main benefit of integrating a business canvas into a PTC course will give students experience with this common visual genre that they may encounter in the entrepreneurial workplace.

\subsection{Next Steps for Researching Business Canvases}

Since so little research on business canvases exists in PTC, a natural first step would be to simply establish how business canvases are used in more detail. Do these two categories really cover all the main uses of business canvases? To investigate this question, individual entrepreneurs could be interviewed or surveyed, or business incubators or accelerators could be investigated to see the role that this genre plays in business generation. Additionally, PTC instructors can experiment with business canvases as a tool for helping students to conceptualize and communicate about businesses. There are obvious pedagogical benefits from teaching students how to use this important genre, and while scholarship has been written on teaching business canvases in other disciplines, there is not scholarship on using a business canvas in PTC courses. Taking these steps, PTC can increase its knowledge of this common form of communication, which plays an important role in business generation and coalition formation globally.

\section{REFERENCES}

[1] Osterwalder, A. (2006, December 13). Business Model Design and Innovation: What is a business model? https://web.archive.org/web/20061213141941/http://businessmodel-design.blogspot.com/2005/11/what-is-business-model.html

[2] Osterwalder, A., \& Pigneur, Y. (2010). Business Model Generation: A Handbook for Visionaries, Game Changers, and Challengers. John Wiley \& Sons.

[3] Sparviero, S. (2019). The Case for a Socially Oriented Business Model Canvas: The Social Enterprise Model Canvas. Journal of Social Entrepreneurship, 10(2), 232-251. https://doi.org/10.1080/19420676.2018.1541011

[4] Daou, A., Mallat, C., Chammas, G., Cerantola, N., Kayed, S., \& Saliba, N. A. (2020). The Ecocanvas as a business model canvas for a circular economy. fournal of Cleaner Production, 258, 120938. https://doi.org/10.1016/j.jclepro.2020.120938

[5] Personal Growth Canvas - Become the best version of yourself with this easy-to-use planning tool. (n.d.). Retrieved May 17, 2021, from https://www. personalgrowthcanvas.com/

[6] Maurya, A. (2012). Running lean: Iterate from plan A to a plan that works. O'Reilly Media.

[7] Business Model Canvas Alternative / LEANSTACK. (2021). https://leanstack.com/ business-

model-canvas-alternative?gclid=CjwKCAjwqIiFBhAHEiwANg9szsbdvoGj3 P665wamhyzJhFSNTyAsPadfHljq0EELp4X2I9h3gXWQ8BoCLHYQAvD_BwE

[8] Coes, B. (2014). CRITICALLY ASSESSING THE STRENGTHS AND LIMITATIONS OF THE BUSINESS MODEL CANVAS. 99.

[9] Ching, H. Y., \& Fauvel, C. (2013). CRITICISMS, VARIATIONS AND EXPERIENCES WITH BUSINESS MODEL CANVAS. 12.

[10] Jackson, W., Scott, D. J., \& Schwagler, N. (2015). Using the Business Model Canvas As A Methods Approach to Teaching Entrepreneurial Finance. JOURNAL OF ENTREPRENEURSHIP EDUCATION, 18(2), 175

[11] Türko, E. S. (2016). Business Plan Vs Business Model Canvas in Entrepreneurship Trainings: A Comparison of Students' Perceptions. Asian Social Science, 12(10), 55. https://doi.org/10.5539/ass.v12n10p55

[12] Fritscher, B., \& Pigneur, Y. (2014). Visualizing Business Model Evolution with the Business Model Canvas: Concept and Tool. 2014 IEEE 16th Conference on Business Informatics, 151-158. https://doi.org/10.1109/CBI.2014.9

[13] Sort, J. C., \& Nielsen, C. (2018). Using the business model canvas to improve investment processes. Journal of Research in Marketing and Entrepreneurship, 20(1), 10-33. https://doi.org/10.1108/JRME-11-2016-0048

[14] International Business Model Competition-Home. (2019, January 12). https://web. archive.org/web/20190112011609/http://www.businessmodelcompetition.com/ 